\title{
As Representações Mentais das Crianças acerca das Figuras Parentais ${ }^{1}$
}

\author{
Susana Custódio \\ Universidade do Porto, Faculdade de Psicologia e de Ciências da Educação \\ Instituto Politécnico de Leiria, Escola Superior de Saúde \\ Orlanda Cruz ${ }^{2}$ \\ Universidade do Porto, Faculdade de Psicologia e de Ciências da Educação
}

\begin{abstract}
RESUMO - Este artigo apresenta uma investigação, realizada em Portugal, sobre a relação entre as representações mentais das crianças acerca dos pais, enquanto figuras de afecto e de disciplina, e a competência social dessas crianças. Participaram no estudo 59 crianças de 8 e 9 anos. As suas representações foram analisadas a partir do conteúdo e da estrutura das narrativas construídas em resposta à Entrevista de Avaliação das Representações das Crianças acerca das Figuras Parentais; a competência social foi avaliada a partir da adaptação portuguesa do Social Skills Rating System - form for teachers, que permite obter valores de habilidades sociais, problemas de comportamento e realização escolar. Os resultados revelam uma relação entre as representações que as crianças têm dos pais como figuras rejeitantes e como figuras punitivas e as habilidades sociais, os problemas internalizados de comportamento e a realização acadêmica, bem como uma relação entre a coerência das representações e a competência social das crianças.
\end{abstract}

Palavras-chave: representações mentais das figuras parentais; crianças de idade escolar; competência social.

\section{Children's Mental Representations of Parental Figures}

\begin{abstract}
This article presents a study, performed in Portugal, about the relationship between child mental representations of parents as affection and disciplinary figures, and child social competence. Fifty-nine children aged 8 and 9 years participated in this research. Their mental representations were analysed by means of the content and structures of narratives elaborated in response to the Children Representations about Parental Figures Interview. Social competence was evaluated with the Portuguese adaptation of the Social Skills Rating System - form for teachers, which allows measuring values of social skills, behaviour problems, and academic competence. The results revealed a relation among children's representations of parents as rejecting and punitive figures and children's social skills, internalizing behaviour problems and school achievement, as well as a relation between the coherence of representations and children's social competence.
\end{abstract}

Keywords: mental representations of parental figures; school-age children; social competence.

As representações mentais das crianças acerca das figuras parentais constituem uma dimensão importante na investigação das interacções pais-filhos. Essas representações são construídas com base nas interacções experienciadas no contexto familiar e influenciam a forma como a criança interpreta a realidade e interage com ela. A idade escolar tem sido o período em que as representações da criança têm sido menos estudadas por comparação com a idade pré-escolar e a adolescência. Porém, é nesta etapa do desenvolvimento que as representações se tornam mais elaboradas e estáveis, relacionando-se com os processos cognitivos e afectivos da criança (Niec \& Russ, 2002).

As representações funcionam como uma espécie de mapa interno que permite ao indivíduo antecipar as res-

1 O presente artigo desenvolve e aprofunda uma comunicação, integrada em um painel temático sobre "Interacções entre pais e filhos", apresentada no contexto do VI Simpósio Nacional de Investigação em Psicologia, Évora, 28 a 30 de Novembro de 2006. Tem como base um estudo empírico desenvolvido no âmbito de uma dissertação de Mestrado em Psicologia, área de especialização em Intervenção Psicológica com Crianças e Adolescentes (Custódio, 2005) e foi parcialmente financiada pela Fundação para a Ciência e a Tecnologia por meio do Centro de Psicologia da Universidade do Porto.

2 Endereço: Faculdade de Psicologia e de Ciências da Educação. Rua Dr. Manuel Pereira da Silva. 4200-392 Porto, Portugal. Tel.: 00351 226079700. Fax: 00351 226079725.E-mail: orlanda@fpce.up.pt. postas dos outros, usando essa informação para guiar o seu comportamento, não só no contexto familiar, mas também nos diversos contextos sociais em que participa (McDowell, Parke \& Spitzer, 2002; Niec \& Russ, 2002; Solomonica-Levi, Yirmiya, Erel, Samet \& Oppenheim, 2001).

Inserindo-se nesse contexto teórico, este artigo apresenta um estudo sobre a relação entre as representações mentais das crianças de idade escolar acerca dos pais enquanto figuras de afecto e de disciplina e a sua competência social, tomando em consideração as variáveis de caracterização sociodemográfica.

A dimensão afectiva do comportamento parental traduz-se num conjunto de comportamentos que visam o prazer, o bem-estar e a satisfação da criança ou a eliminação de qualquer situação geradora de desconforto. Tais comportamentos envolvem a protecção, o cuidado físico e outras manifestações de afecto e de apoio (Khaleque \& Rohner, 2002).

A dimensão disciplinar do comportamento parental traduz-se num conjunto de comportamentos que são utilizados como resposta a uma acção da criança considerada pelos pais como indesejável do ponto de vista social, moral ou convencional (Cruz, 2005, p. 56). Tais comportamentos incluem a afirmação do poder, a indução e a ausência de confronto disciplinar. 
De modo a aceder a uma compreensão mais abrangente e complexa das representações das crianças acerca dos pais importa atender a uma multiplicidade de factores que incluem as influências externas e internas ao contexto familiar. De entre esses factores salientam-se as características sociodemográficas como a idade, o sexo e o nível socioeconómico (NSE).

No respeitante à idade, de um modo geral, as crianças mais velhas avaliam as figuras parentais de um modo mais diferenciado e menos positivo do que as crianças mais novas, de idade pré-escolar (Grych, Wachsmuth-Schlaefer \& Klockow, 2002; Reid, Ramey \& Burchinal, 1990). Com efeito, os progressos da criança de idade escolar, no domínio cognitivo, permitem-lhe, por um lado, elaborar uma reflexão acerca das interacções que estabelece com os pais e, por outro, exprimir as representações que constroem acerca dos mesmos. Essa foi uma das razões que esteve subjacente à escolha da faixa etária dos 8 e 9 anos. Uma outra razão prende-se com o facto da investigação no domínio das representações acerca das figuras parentais tender a incluir crianças de idade pré-escolar e adolescentes, havendo um número mais reduzido de estudos que abranjam as crianças de idade escolar.

No que se refere à diferenciação das representações das crianças em função, quer do seu sexo, quer do sexo dos pais, os resultados das investigações nem sempre são consistentes. Durning e Fortin (2000) constataram que tanto os meninos como as meninas (de 8 e 11 anos) têm uma representação mais positiva da mãe do que do pai. Por sua vez, os meninos, em comparação com as meninas, têm representações mais negativas de ambos os pais. No mesmo sentido, Sorbring, Rödholm-Funnemark e Palmérus (2003) constataram que as crianças têm a percepção dos pais como recorrendo com mais frequência a métodos disciplinares mais severos do que as mães. Por outro lado, quer as raparigas, quer os rapazes, percebem os pais como recorrendo a métodos disciplinares mais austeros em relação aos rapazes do que em relação às raparigas. De referir porém que outros autores não encontraram diferenças nas representações de meninos e meninas acerca dos pais (e.g., Macfie, Toth, Rogosch, Robinson, Emde \& Cicchetti, 1999; Oppenheim, Emde \& Warren, 1997), pelo que as revisões da literatura concluem em geral pela não consistência das diferenças de sexo no que respeita à determinação da parentalidade.

O número de anos de escolaridade dos pais foi utilizado, no estudo que aqui se apresenta, como um indicador de NSE dado tratar-se da variável que, com mais segurança, se associa a diferenças na parentalidade, quer em diferentes culturas, quer em diferentes grupos étnicos (e.g., Hoff, Laursen \& Tardif, 2002; Leaper, 2002). A escolaridade parental tem-se revelado uma variável razoavelmente estável e, em particular, a escolaridade materna é a variável que mais fortemente se associa às diferentes dimensões da parentalidade (e.g., Hoff \& cols., 2002; Richman, Miller \& LeVine, 1992). Os estudos revelam que as crianças provenientes de NSE mais baixo tendem a possuir representações mais negativas dos pais, em termos disciplinares, comparativamente com as crianças de NSE mais elevado (Durning \& Fortin, 2000). Esses dados estão de acordo com a investigação sobre os comportamentos disciplinares dos pais de NSE baixo, que revela que esses utilizam com maior frequência a ameaça, a punição, a desaprovação ou a crítica (Cruz, 1999, 2005; Giles-Sims, Straus \& Sugarman, 1995; Glasgow, Dornbusch, Troyer, Steinberg \& Ritter, 1997; Pinderhughes, Dodge, Bates, Pettit \& Zelli, 2000; Straus \& Stewart, 1999) e evidenciam atitudes e emoções mais negativas nas interacções com os filhos (Rubin \& Mills, 1992) do que pais de NSE alto. Pelo contrário, mães com mais anos de escolaridade manifestam com maior frequência comportamentos disciplinares indutivos e tendem a fornecer informação mais explícita às crianças quando falam com elas do que mães com menos anos de escolaridade (Cruz, 1999; Hoff \& cols., 2002).

No que respeita à relação entre as representações das crianças e a sua competência social, a investigação sugere que as crianças com problemas de comportamento representam as mães como exibindo uma disciplina menos apropriada (Solomonica-Levi \& cols., 2001). As crianças que têm a representação de serem punidas fisicamente tendem a evidenciar menos habilidades sociais e académicas (Shields, Ryan \& Cicchetti, 2001) e mais problemas internalizados de comportamento (Oppenheim \& cols., 1997). No mesmo sentido, quando os pais afirmam recorrer frequentemente à punição física e à agressão verbal como resposta ao comportamento inadequado dos seus filhos, verifica-se uma diminuição no seu bem-estar (Amato \& Fowler, 2002), e nas suas competências de auto-controlo (Cruz, 1999), bem como um aumento nos problemas de comportamento (Lansford \& cols., 2005).

A investigação tem sugerido ainda que as crianças que percebem os pais como rejeitantes e pouco apoiantes evidenciam níveis elevados de ansiedade e de sintomas psicopatológicos (e.g., Muris, Meesters \& van den Berg, 2003). O apoio parental associa-se de forma negativa a comportamentos delinquentes e agressivos (Oppenheim \& cols., 1997) e de forma positiva a comportamentos pró-sociais e de aceitação pelos pares (Shields \& cols., 2001).

Do ponto de vista metodológico, as representações das crianças têm vindo a ser estudadas a partir da construção de narrativas, estimuladas por meio de entrevistas semiestruturadas nas quais são apresentados inícios de histórias que a criança deverá completar (Bretherton \& Oppenheim, 2003; Emde, 2003; Jacobsen \& Hofmann, 1997; Oppenheim \& Waters, 1995). As técnicas que implicam completar histórias desempenham reconhecidamente um papel importante na avaliação da regulação emocional da criança, das suas competências sociais e das suas experiências no contexto familiar (Mueller \& Tingley, 1990; Robinson, Hérot, Haynes \& Mantz-Simmons, 2000).

Foi no âmbito desse quadro conceptual e metodológico que se desenvolveu o presente trabalho com os seguintes objectivos: (a) estudar as representações mentais das crianças acerca das figuras parentais em situações de afecto e em situações de disciplina; (b) estudar essas representações em função de variáveis de carácter sociodemográfico, como o sexo das crianças, o sexo dos pais e a escolaridade destes; (c) estudar a relação entre as representações das crianças acerca das figuras parentais e a sua competência social. 


\section{Método}

\section{Participantes}

Como critérios de selecção e inclusão dos participantes na amostra definimos: frequência do $3 .^{\circ}$ ano do ensino básico; idade compreendida entre 8 e 9 anos; desenvolvimento global adequado ao nível etário; inclusão na turma com o mesmo professor desde o início do ano lectivo; acompanhamento do programa global da turma; viver com ambos os pais ou com figuras substitutas.

Tendo por base os critérios de selecção utilizados, a amostra do nosso estudo foi constituída por 59 crianças, 30 meninos (50.8\%) e 29 meninas (49.2\%). As crianças tinham, em média, 8.4 anos ( $\mathrm{DP}=0.5$; sendo o mínimo 8 e o máximo 9 anos) e frequentavam oito escolas da Zona Metropolitana do Porto. A média de anos de escolaridade das mães era de $9.8(\mathrm{DP}=4.63$; sendo o mínimo 4 e o máximo 17 anos $)$ e a média de anos de escolaridade dos pais era de $9.7(\mathrm{DP}=4.29$; variando igualmente entre 4 e 17 anos). O número de anos de escolaridade da mãe e do pai encontram-se intercorrelacionados de forma positiva e estatisticamente significativa $(\mathrm{r}=.78$; $\mathrm{p}<.0005$ ), pelo que as análises posteriores serão realizadas apenas com a variável anos de escolaridade da mãe.

Participaram também no estudo as 10 professoras das crianças participantes como avaliadoras da sua competência social.

\section{Instrumentos}

\section{Entrevista de avaliação das representações das crianças acerca das figuras parentais}

Neste estudo, as representações das crianças foram estudadas a partir de uma entrevista semi-estruturada que designámos Entrevista de Avaliação das Representações das Crianças acerca das Figuras Parentais ${ }^{3}$, elaborada com base na MacArthur Story Stem Battery (MSSB) (Bretherton \& Oppenheim, 2003; Bretherton, Oppenheim, Buchsbaum, Emde \& the MacArthur Narrative Group, 1990), e que pretende estimular, a partir de inícios de histórias, a elaboração das narrativas pelas crianças (Custódio, 2005).

A Entrevista é constituída por 10 inícios de histórias e por um conjunto de perguntas orientadoras da narrativa. Existem duas versões paralelas, uma relativa à figura materna e outra relativa à figura paterna. Os inícios das histórias são formulados na terceira pessoa, sendo que toda a entrevista se refere ao/à protagonista (criança da mesma idade e do mesmo sexo da criança entrevistada) e não à criança directamente. Os conteúdos das histórias versam episódios de conflito muito próximos das interacções quotidianas habituais entre pais e filhos e incluem dois tipos de temáticas: uma temática disciplinar e uma temática afectiva, sendo uma delas dominante em cada história. Desse modo, em cinco histórias a temática dominante é a disciplinar, enquanto nas outras cinco a temática dominante é a afectiva. As "histórias disciplinares" traduzem

3 De forma a facilitar a leitura, futuramente utilizaremos a designação Entrevista para nos referirmos à Entrevista de Avaliação das Representações das Crianças acerca das Figuras Parentais. episódios em que a criança protagonista apresenta um comportamento socialmente inadequado e as "histórias afectivas" traduzem episódios em que a criança protagonista é descrita como estando numa situação de vulnerabilidade física e/ou emocional. As perguntas colocadas às crianças, sempre que necessário para a elaboração da narrativa, são as seguintes: (1) Como é que achas que o(a) menino(a) se sente? Porquê?, (2) E a mãe/pai, como é que achas que ela/e se sente? Porquê?, (3) O que é que achas que a mãe/pai vai fazer?, (4) Porque é que achas que agiu dessa forma?, (5) E agora como é que o(a) menino(a) se sente?, (6) E agora como é que achas que a mãe/pai se sente?, e (7) Como termina a história?. Com o objectivo de conferir um carácter lúdico e estimular a elaboração da narrativa, são utilizadas oito figuras ilustrativas (em papel plastificado) das personagens envolvidas.

No Quadro 1 sistematizam-se as histórias, o seu conteúdo, temática disciplinar, temática afectiva e temática dominante.

A administração da Entrevista foi realizada de acordo com o Manual de Administração da Entrevista ${ }^{4}$. Neste são definidas as condições de aplicação de modo a que a apresentação das histórias seja realizada de forma estandardizada, mas flexível.

Sistema de codificação das narrativas. A elaboração do sistema de codificação da Entrevista ${ }^{5}$ teve como base a análise de conteúdo das narrativas elaboradas pelas crianças participantes num estudo-piloto, bem como o MacArthur Narrative Coding Manual (Bretherton \& Oppenheim, 2003; Robinson, Mantz-Simmons, Macfie, Kelsay \& the MacArthur Narrative Working Group, 2001). O sistema de codificação das narrativas teve em conta, quer as dimensões do conteúdo propriamente dito (comportamentos de afecto e comportamentos disciplinares), quer as dimensões da estrutura narrativa (coerência narrativa, coerência emocional e conclusão da narrativa).

No Quadro 2 apresenta-se o sistema de codificação com as categorias de resposta incluídas em cada dimensão. Em cada narrativa construída pela criança, para cada dimensão foi registada apenas uma categoria.

O conteúdo da narrativa traduz as representações acerca dos comportamentos das figuras parentais em termos de afecto e de disciplina. Na dimensão comportamentos parentais de afecto identificaram-se três categorias.

- Rejeição: representação negativa acerca do comportamento parental, como por exemplo, manifestar insensibilidade ao estado físico ou aos desejos da criança, afastar a criança e desaprovar o seu comportamento;

- Neutralidade: representação da figura parental como lidando com a situação apresentada de forma neutra, não havendo indicadores objectivos nem de rejeição nem de aceitação da criança;

- Aceitação: representação positiva acerca do comportamento parental, como por exemplo, proteger a criança, prestar

4 O Manual de Administração da Entrevista poderá ser disponibilizado ao leitor interessado.

5 O Manual de Codificação da Entrevista poderá ser disponibilizado ao leitor interessado. 
Quadro 1. Histórias, conteúdo, temática disciplinar, temática afectiva e temática dominante.

\begin{tabular}{|c|c|c|c|c|}
\hline Histórias & Conteúdo & Temática Disciplinar & Temática Afectiva & Dominante \\
\hline História 1 & $\begin{array}{l}\text { Insistência da criança em ir } \\
\text { para casa interrompendo uma } \\
\text { conversa entre adultos. }\end{array}$ & $\begin{array}{l}\text { Conflito de interesses entre a } \\
\text { criança e a figura parental. }\end{array}$ & $\begin{array}{l}\text { Sentimento de frustração } \\
\text { resultante da privação de uma } \\
\text { actividade do seu agrado. }\end{array}$ & Disciplinar \\
\hline História 2 & $\begin{array}{l}\text { Queda da bicicleta devido a } \\
\text { descuido. }\end{array}$ & $\begin{array}{l}\text { Envolvimento em } \\
\text { comportamento que envolve } \\
\text { algum risco físico. }\end{array}$ & $\begin{array}{l}\text { Necessidade de apoio dado ter- } \\
\text { se magoado - fragilidade física. }\end{array}$ & Afectiva \\
\hline História 3 & $\begin{array}{l}\text { Insistência da criança para } \\
\text { cantar à mesa. }\end{array}$ & $\begin{array}{l}\text { Desobediência às ordens } \\
\text { parentais. }\end{array}$ & $\begin{array}{l}\text { Sentimento de frustração face à } \\
\text { impossibilidade de prosseguir } \\
\text { uma actividade do seu agrado. }\end{array}$ & Disciplinar \\
\hline História 4 & $\begin{array}{l}\text { Realização de batota numa } \\
\text { situação de jogo com os pares. }\end{array}$ & $\begin{array}{l}\text { Não cumprimento das regras no } \\
\text { jogo com os pares, presenciado } \\
\text { pela figura parental. }\end{array}$ & $\begin{array}{l}\text { Rejeição pelos pares após ter } \\
\text { feito batota, ficando excluído/a } \\
\text { do grupo. }\end{array}$ & Afectiva \\
\hline História 5 & $\begin{array}{l}\text { Agressão física a um/a colega } \\
\text { numa situação de jogo. }\end{array}$ & $\begin{array}{l}\text { Conflito com os pares } \\
\text { presenciado pela figura parental. }\end{array}$ & $\begin{array}{l}\text { Sentimento de frustração face à } \\
\text { possibilidade de perder o jogo. }\end{array}$ & Disciplinar \\
\hline História 6 & $\begin{array}{l}\text { Incapacidade de resolução dos } \\
\text { trabalhos de casa devido à falta } \\
\text { de atenção na sala de aula. }\end{array}$ & $\begin{array}{l}\text { Comportamento inadequado no } \\
\text { contexto da sala de aula. }\end{array}$ & $\begin{array}{l}\text { Vulnerabilidade emocional } \\
\text { resultante da dificuldade de } \\
\text { resolução dos trabalhos de casa. }\end{array}$ & Afectiva \\
\hline História 7 & $\begin{array}{l}\text { Conflito com o/a irmão/ã } \\
\text { derivado do desejo de jogar } \\
\text { computador em primeiro lugar. }\end{array}$ & $\begin{array}{l}\text { Agressão física ao/à irmão/irmã } \\
\text { presenciada pela figura parental. }\end{array}$ & $\begin{array}{l}\text { Sentimento de frustração } \\
\text { resultante do facto de não } \\
\text { ser o/a primeiro/a a jogar no } \\
\text { computador. }\end{array}$ & Disciplinar \\
\hline História 8 & $\begin{array}{l}\text { Obtenção de uma nota mais } \\
\text { baixa que o habitual e oferta de } \\
\text { uma prenda à figura parental. }\end{array}$ & $\begin{array}{l}\text { Resultados escolares inferiores } \\
\text { aos habituais. }\end{array}$ & $\begin{array}{l}\text { Oferta de uma prenda realizada } \\
\text { pela criança. Sentimento de } \\
\text { frustração face aos resultados } \\
\text { escolares. }\end{array}$ & Afectiva \\
\hline História 9 & $\begin{array}{l}\text { Roubo de um chocolate no } \\
\text { supermercado. }\end{array}$ & $\begin{array}{l}\text { Roubo de um chocolate } \\
\text { presenciado pela figura parental. }\end{array}$ & $\begin{array}{l}\text { Desejo da criança de obter um } \\
\text { chocolate. }\end{array}$ & Disciplinar \\
\hline História 10 & $\begin{array}{l}\text { A criança põe a mesa para fazer } \\
\text { uma surpresa à figura parental, } \\
\text { mas parte um copo. }\end{array}$ & $\begin{array}{l}\text { Falta de cuidado da criança } \\
\text { donde resulta o corpo partido. }\end{array}$ & $\begin{array}{l}\text { Realização de uma surpresa: pôr } \\
\text { a mesa. Sentimento de tristeza } \\
\text { por ter partido o copo. }\end{array}$ & Afectiva \\
\hline
\end{tabular}

cuidados de saúde, manifestar comportamentos de apoio e de afecto, e satisfazer os desejos da criança.

$\mathrm{Na}$ dimensão comportamentos parentais disciplinares identificaram-se cinco categorias.

- Punição física: representação de comportamentos parentais que implicam o castigo físico como forma de exercer controlo sobre a criança;

- Punição não física: representação de comportamentos parentais que envolvem castigos não físicos, como a ameaça de castigo, a retirada de privilégios e a repreensão verbal;
- Instrução directa: representação de comportamentos parentais que visam indicar à criança comportamentos adequados numa determinada situação, sem no entanto ser apresentada qualquer explicação para isso;

- Indução: representação de comportamentos parentais que incluem o uso de explicações ou de justificações, que visam enunciar um princípio de acção ou um comportamento alternativo a utilizar em situações futuras;

- Ausência de confronto: representação do comportamento parental caracterizado por ignorar a situação de conflito, 
Quadro 2. Dimensões e categorias de resposta.

\begin{tabular}{|c|c|c|}
\hline & Dimensões & Categorias de Resposta \\
\hline \multirow[b]{2}{*}{ Conteúdo } & I. Comportamentos parentais de afecto & $\begin{array}{l}\text { 1. Rejeição } \\
\text { 2. Neutralidade } \\
\text { 3. Aceitação }\end{array}$ \\
\hline & II. Comportamentos parentais disciplinares & $\begin{array}{l}\text { 1. Punição física } \\
\text { 2. Punição não física } \\
\text { 3. Instrução directa } \\
\text { 4. Indução } \\
\text { 5. Ausência de confronto }\end{array}$ \\
\hline \multirow{3}{*}{ Estrutura } & IV. Coerência emocional & $\begin{array}{l}\text { 1. Incoerência emocional } \\
\text { 2. Evitamento das emoções positivas } \\
\text { 3. Evitamento das emoções negativas } \\
\text { 4. Coerência emocional }\end{array}$ \\
\hline & V. Coerência narrativa & $\begin{array}{l}\text { 1. Resolução bizarra } \\
\text { 2. Resolução inadequada ou inexistente } \\
\text { 3. Resolução mágica } \\
\text { 4. Coerência narrativa }\end{array}$ \\
\hline & VI. Conclusão da narrativa & $\begin{array}{l}\text { 1. Conclusão negativa } \\
\text { 2. Conclusão neutra } \\
\text { 3. Conclusão positiva }\end{array}$ \\
\hline
\end{tabular}

havendo cedência às solicitações da criança para evitar o confronto.

A estrutura da narrativa traduz o modo como os acontecimentos e as diferentes partes de uma narrativa estão interrelacionados e organizados de forma lógica, coerente e significativa, incluindo quer a coerência emocional, quer a coerência narrativa (Cain, 2003; Carlson, Sroufe \& Egeland, 2004). A coerência emocional compreende a congruência do afecto com o conteúdo, ou seja, a adequação entre acções ou pensamentos e as emoções expressas em relação a estes. Nessa dimensão consideraram-se quatro categorias.

- Incoerência emocional: expressão de estados emocionais não adaptados aos comportamentos relatados e/ou à situação, mudança repentina de emoções sem justificação adequada e apresentação de estados emocionais diferentes mas justificados do mesmo modo;

- Evitamento das emoções positivas: ênfase na valência emocional negativa da história. Esta categoria é utilizada quando, nas "histórias afectivas", o tema dominante (afectivo) não é abordado, sendo substituído pelo tema disciplinar;

- Evitamento das emoções negativas: ênfase na valência emocional positiva da história. Esta categoria é utilizada quando, nas "histórias disciplinares", o tema dominante (disciplinar) não é abordado, sendo substituído pelo tema afectivo;

- Coerência emocional: expressão de emoções congruentes com os comportamentos relatados e/ou as situações apresentadas.

A coerência narrativa compreende a consistência interna (a interligação entre as diferentes partes da narrativa), a organização (a ordem e a sequência da narrativa) e a flexibilidade (a integração de diferentes perspectivas). Relativamente a esta dimensão, identificaram-se quatro categorias.

- Resolução bizarra: resolução não adaptativa face à situação apresentada.

- Resolução inadequada ou inexistente: não é apresentada qualquer resolução da situação quando esta é esperada ou é apresentada uma resolução inadequada;

- Resolução mágica: assiste-se a um saltar do problema para a conclusão sem qualquer explicitação das etapas intermédias;

- Coerência narrativa: apresentação de uma resolução construtiva e adaptativa do conflito com a explicitação de uma sequência de eventos relacionados.

Por último, no que respeita à dimensão conclusão da narrativa, tomando em consideração a perspectiva da criança, identificaram-se três categorias.

- Conclusão negativa: inclui temas como frustração, punição, medo, aborrecimento, destruição ou luta;

- Conclusão neutra: não está presente qualquer carga emocional, positiva ou negativa;

- Conclusão positiva: inclui uma sensação de satisfação dos desejos e dos interesses da criança.

Análise do acordo intercodificador. As narrativas de 25\% dos participantes, ou seja de 15 crianças (300 narrativas), foram codificadas independentemente pelas duas autoras para efeitos da avaliação da fidelidade intercodificador. Procedeu-se ao cálculo do coeficiente de acordo ${ }^{6}$ e do valor do Kappa (Cohen's Kappa) para cada uma das diferentes categorias identificadas (Chuang, 2001). Para as 19 categorias

6 Número acordos $/ \mathrm{n} .{ }^{\circ}$ acordos + n. ${ }^{\circ}$ desacordos 
referidas, o coeficiente de acordo oscilou entre $85 \%$ e $100 \%$, sendo a média de $95 \%$. Relativamente ao Kappa, a média foi de .70, verificando-se uma variação entre .22 (categorias menos frequentadas) e 1.00. Podemos concluir que o valor elevado dos coeficientes de acordo oferece uma boa garantia da fidelidade do sistema de codificação, sendo passível de ser utilizado com confiança por várias pessoas, desde que treinadas especificamente para tal.

\section{Escalas de Avaliação da Competência Social}

Com o objectivo de avaliar a competência social das crianças de idade escolar, foi pedido às professoras que preenchessem as Escalas de Avaliação da Competência Social (forma para professores), versão para crianças entre os $5 \mathrm{e}$ os 12 anos (Lemos \& Meneses, 2002), que é um instrumento adaptado a partir do Social Skills Rating System (SSRS) (Gresham \& Elliott, 1990).

As Escalas de Avaliação da Competência Social são três: a escala de habilidades sociais (avalia as dimensões cooperação, asserção e auto-controlo), a escala de problemas de comportamento (avalia os problemas externalizados, os problemas internalizados e a hiperactividade) e a escala de competência académica (avalia o desempenho na leitura e na matemática). As duas primeiras têm uma escala de resposta de três pontos, enquanto que a terceira é avaliada segundo uma escala de resposta de cinco pontos. A consistência interna das notas (alpha de Cronbach) é bastante elevada: 0.96 para a escala de habilidades sociais, 0.90 para a escala de problemas de comportamento e 0.98 para a escala de competência académica. As notas das três escalas não se diferenciaram estatisticamente em função do sexo das crianças. Verificou-se uma associação significativa positiva entre os anos de escolaridade das mães e as escalas de habilidades sociais $(r=.41$, $\mathrm{p}<.01)$ e de competência académica $(\mathrm{r}=.43, \mathrm{p}<.01)$.

\section{Procedimento}

A Entrevista foi aplicada individualmente em um espaço disponibilizado pela escola frequentada por cada criança, garantindo a confidencialidade das informações recolhidas. Antes da apresentação das histórias era dito à criança que não existiam respostas certas nem erradas e que a Entrevista não tinha qualquer carácter de avaliação com propósitos escolares.

Após a apresentação de cada história, caso a criança não começasse, por sua iniciativa, a elaboração da narrativa, o entrevistador colocava-lhe as sete questões atrás enunciadas, pela ordem estabelecida no manual de administração. O entrevistador deveria certificar-se que a narrativa da criança incluía informação relativa a como se sentem as personagens nos dois momentos (antes e depois da intervenção parental), o que fazem e como acaba a história. Se a criança hesitasse em responder, era encorajada a continuar por meio de questões abertas, usadas para facilitar a sua narrativa, seguindo-se os procedimentos da entrevista semi-estruturada.

$\mathrm{Na}$ administração da Entrevista, as histórias afectivas e as histórias disciplinares eram apresentadas de forma alternada, balanceando-se a ordem de apresentação das histórias relativas à figura paterna e à figura materna, que eram apresentadas em bloco. Cada criança elaborou assim um total de 20 narrativas. A administração da Entrevista demorou, em média, 60 minutos, sendo todo o procedimento gravado em áudio para, posteriormente, se proceder à transcrição, análise e codificação das narrativas construídas pelas crianças. De um modo geral, as crianças manifestaram bastante interesse e envolvimento na elaboração das narrativas, revelando-se assim a Entrevista um instrumento de fácil administração.

As Escalas de Avaliação da Competência Social foram preenchidas pela professora de cada uma das crianças participantes, verificando-se uma atitude de total colaboração.

\section{Resultados}

Em um primeiro momento, tendo em vista a análise da distribuição das narrativas das crianças pelas várias categorias de resposta contempladas no sistema de codificação, apresentam-se na Tabela 1 as estatísticas descritivas.

A análise da distribuição das categorias permite verificar que, de um modo geral, as representações das crianças acerca do comportamento de afecto, quer da figura materna, quer da figura paterna, se distribuem de forma razoavelmente homogénea entre as categorias de rejeição e de aceitação, sendo a categoria de neutralidade menos frequente. Relativamente ao comportamento disciplinar, quer da figura materna, quer da figura paterna, a categoria mais frequente é a ausência de confronto. Seguem-se as acções de carácter punitivo intermédio - punição não física e instrução directa - sendo a punição física e a indução as categorias menos referidas pelas crianças.

Relativamente à estrutura da narrativa elaborada pelas crianças, e ao nível emocional, verificou-se que a maior parte das narrativas são avaliadas como possuindo coerência emocional; porém, um número considerável de narrativas é também marcado pela incoerência emocional. Do ponto de vista narrativo, pode-se constatar que, na sua maioria, as narrativas apresentam uma resolução construtiva, característica da coerência narrativa, constatando-se uma frequência significativa da categoria resolução inadequada ou inexistente. Relativamente à conclusão da narrativa, verifica-se que as conclusões apresentadas pelas crianças são, na sua maioria, positivas.

Os resultados obtidos permitiram concluir acerca da existência de variabilidade suficiente nas respostas das crianças e, deste modo, prosseguir com a análise dos resultados.

Assim, em um segundo momento, com o objectivo de analisar as representações das crianças em função do sexo das figuras parentais, procedeu-se a uma análise comparativa das médias das respostas dadas pelas crianças face à figura materna e face à figura paterna (teste $t$ para amostras emparelhadas) e a uma análise das correlações entre estas representações (coeficiente de correlação de Pearson). Essa informação aparece descrita na Tabela 2.

Verificou-se que, à excepção do evitamento das emoções negativas, não ocorreram diferenças entre as narrativas das crianças face às figuras materna e paterna. As correlações entre as categorias relativas às duas figuras são todas positivas e estatisticamente significativas, o que nos permite concluir pela razoável similitude das representações que as crianças 
Tabela 1. Distribuição das narrativas das crianças pelas categorias de resposta.

\begin{tabular}{|c|c|c|c|c|c|c|c|}
\hline \multirow{2}{*}{ Dimensões } & \multirow{2}{*}{ Categorias } & \multicolumn{3}{|c|}{ Figura materna } & \multicolumn{3}{|c|}{ Figura paterna } \\
\hline & & $\mathbf{N}$ & $\%$ & Amplitude & $\mathbf{N}$ & $\%$ & Amplitude \\
\hline \multirow{4}{*}{$\begin{array}{l}\text { Comportamentos de } \\
\text { Afecto }\end{array}$} & Rejeição & 233 & 39,5 & $1-7$ & 240 & 40,7 & $0-8$ \\
\hline & Neutralidade & 112 & 19,0 & $0-5$ & 108 & 18,3 & $0-7$ \\
\hline & Aceitação & 245 & 41,5 & $2-7$ & 242 & 41,0 & $0-8$ \\
\hline & Total & 590 & 100 & & 590 & 100 & \\
\hline \multirow{6}{*}{$\begin{array}{l}\text { Comportamentos } \\
\text { Disciplinares }\end{array}$} & Punição física & 36 & 6,1 & $0-5$ & 39 & 6,6 & $0-5$ \\
\hline & Punição não física & 146 & 24,7 & $0-8$ & 147 & 24,9 & $0-7$ \\
\hline & Instrução directa & 113 & 19,2 & $0-7$ & 115 & 19,5 & $0-6$ \\
\hline & Indução & 44 & 7,5 & $0-4$ & 48 & 8,1 & $0-7$ \\
\hline & Ausência de confronto & 251 & 42,5 & $1-8$ & 241 & 40,9 & $1-9$ \\
\hline & Total & 590 & 100 & & 590 & 100 & \\
\hline \multirow{5}{*}{ Coerência Emocional } & Incoerência emocional & 124 & 21,0 & $0-10$ & 123 & 20,9 & $0-9$ \\
\hline & Evitamento das emoções positivas & 70 & 11,9 & $0-3$ & 76 & 12,9 & $0-3$ \\
\hline & Evitamento das emoções negativas & 45 & 7,6 & $0-3$ & 32 & 5,4 & $0-3$ \\
\hline & Coerência emocional & 351 & 59,5 & $0-10$ & 359 & 60,8 & $1-10$ \\
\hline & Total & 590 & 100 & & 590 & 100 & \\
\hline \multirow{5}{*}{ Coerência Narrativa } & Resolução bizarra & 8 & 1,4 & $0-5$ & 10 & 1,7 & $0-5$ \\
\hline & Resolução inadequada ou inexistente & 156 & 26,4 & $0-9$ & 139 & 23,5 & $0-8$ \\
\hline & Resolução mágica & 61 & 10,3 & $0-7$ & 57 & 9,7 & $0-4$ \\
\hline & Coerência narrativa & 365 & 61,9 & $1-10$ & 384 & 65,1 & $0-10$ \\
\hline & Total & 590 & 100 & & 590 & 100 & \\
\hline \multirow{4}{*}{$\begin{array}{l}\text { Conclusão da } \\
\text { Narrativa }\end{array}$} & Conclusão negativa & 52 & 8,8 & $0-8$ & 47 & 8,0 & $0-7$ \\
\hline & Conclusão neutra & 95 & 16,1 & $0-5$ & 111 & 18,8 & $0-5$ \\
\hline & Conclusão positiva & 443 & 75,1 & $0-10$ & 432 & 73,2 & $2-10$ \\
\hline & Total & 590 & 100 & & 590 & 100 & \\
\hline
\end{tabular}

Tabela 2. Correlações entre as categorias de resposta relativas à figura materna e à figura paterna, médias (M), desvios-padrão (DP) e valor $t$ em função do sexo dos pais.

\begin{tabular}{|c|c|c|c|c|c|}
\hline Dimensões & Categorias & $\begin{array}{l}\text { Correlações } \\
\text { mãe/pai }\end{array}$ & $\begin{array}{c}\text { Figura } \\
\text { paterna } \\
\text { M }(D P)\end{array}$ & $\begin{array}{c}\text { Figura } \\
\text { materna } \\
\text { M }(D P)\end{array}$ & $t$ \\
\hline \multirow{3}{*}{ Comportamentos de Afecto } & Rejeição & $0,812 * * *$ & $4,07(1,85)$ & $3,95(1,73)$ & 0,829 \\
\hline & Neutralidade & $0,675 * * *$ & $1,83(1,66)$ & $1,90(1,46)$ & $-0,410$ \\
\hline & Aceitação & $0,706 * * *$ & $4,10(1,47)$ & $4,15(1,30)$ & $-0,364$ \\
\hline \multirow{5}{*}{ Comportamentos Disciplinares } & Punição física & $0,624 * * *$ & $0,66(1,25)$ & $0,61(1,26)$ & 0,358 \\
\hline & Punição não física & $0,754 * * *$ & $2,49(1,95)$ & $2,47(1,96)$ & 0,095 \\
\hline & Instrução directa & $0,763 * * *$ & $1,95(1,83)$ & $1,92(1,67)$ & 0,214 \\
\hline & Indução & $0,629 * * *$ & $0,81(1,35)$ & $0,75(1,04)$ & 0,489 \\
\hline & Ausência de confronto & $0,747 * * *$ & $4,08(1,72)$ & $4,25(1,85)$ & $-1,021$ \\
\hline \multirow{4}{*}{ Coerência Emocional } & Incoerência emocional & $0,636^{* * *}$ & $2,08(2,33)$ & $2,10(2,03)$ & $-0,069$ \\
\hline & Evitamento das emoções positivas & $0,699 * * *$ & $1,29(0,89)$ & $1,19(0,88)$ & 1,137 \\
\hline & Evitamento das emoções negativas & $0,522 * * *$ & $0,54(0,77)$ & $0,76(0,80)$ & $-2,206^{*}$ \\
\hline & Coerência emocional & $0,699 * * *$ & $6,08(2,17)$ & $5,95(2)$ & 0,641 \\
\hline \multirow{4}{*}{ Coerência Narrativa } & Resolução bizarra & $0,799 * * *$ & $0,17(0,72)$ & $0,14(0,71)$ & 0,574 \\
\hline & Não resolvida & $0,756^{* * *}$ & $2,36(2,09)$ & $2,64(2,24)$ & $-1,456$ \\
\hline & Resolução inadequada ou inexistente & $0,480 * * *$ & $0,97(1,05)$ & $1,03(1,47)$ & $-0,389$ \\
\hline & Coerência narrativa & $0,754 * * *$ & $6,51(2,52)$ & $6,19(2,60)$ & 1,378 \\
\hline \multirow{3}{*}{ Conclusão da Narrativa } & Conclusão negativa & $0,673 * * *$ & $0,80(1,41)$ & $0,88(1,46)$ & $-0,559$ \\
\hline & Conclusão neutra & $0,270^{*}$ & $1,88(1,46)$ & $1,61(1,37)$ & 1,218 \\
\hline & Conclusão positiva & $0,447 * * *$ & $7,32(1,77)$ & $7,51(2,04)$ & $-0,712$ \\
\hline
\end{tabular}

$* \mathrm{p}<0,05 \quad * * * \mathrm{p}<0,0005$ 
têm das figuras materna e paterna. Desse modo, atendendo por um lado à ausência de diferenças estatisticamente significativas entre as representações das crianças face à figura materna e face à figura paterna $\mathrm{e}$, por outro, à forte correlação entre as mesmas, optou-se por utilizar uma medida única - a média - para cada uma das categorias, traduzindo a representação das crianças face a ambas as figuras parentais. As análises subsequentes foram, portanto, realizadas utilizando essa medida.

Em um terceiro momento, pretendendo-se verificar a existência de diferenças nas representações acerca das figuras parentais em função do sexo da criança, foi realizado um teste $t$ para amostras independentes. Não foram verificadas, na generalidade das categorias, diferenças de médias significativas entre rapazes e raparigas.

Em um quarto momento, com o objectivo de estudar a relação entre as representações das crianças e o nível de escolaridade dos pais, analisou-se a correlação entre esses dois tipos de variáveis (coeficiente de Pearson). Essa informação aparece descrita na Tabela 3.

Os resultados revelam que as crianças cujos pais possuem um maior número de anos de escolaridade apresentam narrativas que traduzem representações de comportamentos de afecto mais positivo e comportamentos disciplinares menos punitivos e elaboram narrativas mais coerentes. A análise da Tabela 3 permite verificar que, de uma maneira geral, as correlações são mais fortes quando se considera a escolaridade das mães, o que está de acordo com estudos já referenciados na literatura (Hoff \& cols., 2002).
Por último, analisámos a relação entre as narrativas construídas pelas crianças e a sua competência social. Uma vez que a variável anos de escolaridade da mãe se correlaciona, quer com as representações das crianças, quer com a sua competência social, as correlações foram calculadas controlando os efeitos dessa variável (correlação parcial). $\mathrm{Na}$ Tabela 4 apresentam-se os valores das correlações entre as categorias de resposta e as notas das Escalas de Avaliação da Competência Social, antes e depois de controlar a escolaridade das mães.

Constatou-se que a representação dos comportamentos parentais de aceitação não se encontra associada de forma significativa a qualquer das escalas de competência social. Por outro lado, as crianças que apresentam mais representações de rejeição parental são avaliadas pelas professoras como revelando menos comportamentos de auto-controlo e de asserção, mais problemas internalizados de comportamento e como sendo menos competentes em termos académicos. De referir que a relação entre a representação de rejeição e as dimensões asserção e problemas internalizados de comportamento se mantém, mesmo depois de controlada a escolaridade da mãe; pelo contrário, a correlação entre a representação de rejeição e as dimensões de auto-controlo e competência académica deixa de ser significativa.

Relativamente aos comportamentos disciplinares, a percepção de punição física correlaciona-se de forma negativa e significativa com as três dimensões da escala de habilidades sociais e com a competência académica, e de forma positiva com os problemas internalizados de com-

Tabela 3. Correlações entre as categorias de resposta e a escolaridade da mãe e do pai.

\begin{tabular}{llcc}
\hline Dimensões & Categorias & Escolaridade Mãe & Escolaridade Pai \\
\hline \multirow{4}{*}{ Comportamentos de Afecto } & Rejeição & $-0,323^{*}$ & $-0,268^{*}$ \\
& Neutralidade & $0,396^{* *}$ & $0,378^{* *}$ \\
& Aceitação & $-0,013$ & $-0,067$ \\
\hline \multirow{4}{*}{ Comportamentos Disciplinares } & Punição física & $-0,283^{*}$ & $-0,291^{*}$ \\
& Punição não física & $-0,210$ & $-0,199$ \\
& Instrução directa & $0,436^{* *}$ & $0,385^{* *}$ \\
& Indução & $0,284^{*}$ & 0,212 \\
& Ausência de confronto & $-0,192$ & $-0,101$ \\
\hline \multirow{5}{*}{ Coerência Emocional } & Incoerência emocional & $-0,279^{*}$ & $-0,174$ \\
& Evitamento das emoções positivas & $-0,140$ & $-0,166$ \\
& Evitamento das emoções negativas & $-0,131$ & $-0,283^{*}$ \\
& Coerência emocional & $0,393^{* *}$ & $0,350^{* *}$ \\
\hline \multirow{5}{*}{ Coerência Narrativa } & Resolução bizarra & $-0,127$ & $-0,082$ \\
& Resolução inadequada ou inexistente & $-0,427^{* *}$ & $-0,292^{*}$ \\
& Resolução mágica & $-0,009$ & 0,155 \\
& Coerência narrativa & $0,401^{* *}$ & 0,200 \\
\hline \multirow{3}{*}{ Conclusão da Narrativa } & Conclusão negativa & $-0,239$ & $-0,142$ \\
& Conclusão neutra & $-0,254$ & $-0,211$ \\
& Conclusão positiva & $0,371^{* *}$ & $0,262^{*}$ \\
\hline
\end{tabular}

${ }^{*} \mathrm{p}<0,05 \quad * * \mathrm{p}<0,01$ 
portamento. As crianças que representam os pais como mais punitivos (fisicamente) são avaliadas pelas professoras como sendo menos competentes em termos sociais e académicos e como apresentando mais problemas internalizados de comportamento; essas crianças não foram referidas pelas professoras como evidenciando problemas externalizados de comportamento.

No que respeita à estrutura narrativa, as crianças que constroem narrativas mais coerentes são avaliadas pelas professoras como mais competentes em termos sociais e académicos.

\section{Discussão}

Ao estimular as crianças a desenvolver narrativas com base em situações de interacção quotidianas, pretende-se aceder às suas representações relativas às figuras parentais (Mueller \& Tingley, 1990). Os resultados obtidos permitem concluir que as histórias que integram a Entrevista estimularam uma diversidade razoável de respostas por parte das crianças.

As crianças que participaram neste estudo construíram narrativas muito semelhantes face às figuras materna e paterna, quer em termos de conteúdo, quer em termos de estrutura. Os resultados traduzem uma elevada consistência intra-individual nas representações da criança sobre a mãe e sobre o pai enquanto figuras de afecto e de disciplina. Daqui se conclui que, de um modo geral, as crianças não fizeram distinções entre os papéis tradicionalmente associados à figura materna (afecto) e à figura paterna (disciplina). A similaridade das representações parece sugerir que as crianças tendem a representar a mãe e o pai como uma unidade parental, ou pelo menos, tendem a ter modelos semelhantes, em relação a ambas as figuras (Macfie \& cols., 1999; Oppenheim \& cols., 1997). Em termos práticos, esses resultados levantam a possibilidade de utilizar apenas uma versão do instrumento referente, ou à mãe, ou ao pai, para aceder às representações das crianças, o que traduziria benefícios em termos da quantidade de tempo dispendido na administração da Entrevista.

No que se refere às diferenças nas representações acerca das figuras parentais em função do sexo das crianças, verificámos, na generalidade das categorias, que as raparigas e os rapazes tendem a ter representações similares. Esses resultados são consistentes com os obtidos por Oppenheim e cols. (1997) e por Macfie e cols. (1999), que não constataram diferenças nas representações das crianças em função do seu sexo. A ausência desse tipo de diferenças, quer nas crianças, quer em relação às figuras parentais, leva-nos a pensar que, possivelmente, na geração actual, ao contrário das gerações anteriores, os papéis de género tendem a ser mais igualitários. De facto, os resultados dos estudos nem sempre apontam na mesma direcção e serão necessárias mais investigações para suportar a necessária análise sociológica e retirar conclusões que, dada a natureza dinâmica da nossa sociedade, serão sempre conclusões provisórias.

A análise das relações entre as representações das crianças e a escolaridade dos pais permite concluir que os filhos de pais com menos anos de escolaridade percepcionam as figuras parentais como mais rejeitantes, fisicamente punitivas e menos indutivas. Esses resultados são congruentes com os obtidos em estudos no âmbito da parentalidade (Cruz, 1999; Giles-Sims \& cols., 1995; Straus \& Stewart, 1999). Apesar de neste estudo não termos observado directamente o comportamento parental, o facto de as representações das crianças serem coerentes com o que a literatura tem demonstrado acerca da influência do NSE na parentalidade, leva-nos a apoiar a ideia de que as representações das crianças são de facto construídas com base nas suas interacções quotidianas. Pais com um nível de escolaridade mais baixo aparentemente estão menos sensíveis às necessidades das crianças e mais predispostos para reprovar o seu comportamento, actuar de forma coerciva, explicando pouco à criança as razões da sua actuação (Cruz, 1999; Hoff \& cols., 2002; Pinderhughes \& cols., 2000). Os filhos de pais com nível de escolaridade mais baixo traduzem nas suas narrativas esse tipo de representação. Porém, a escolaridade dos pais não se reflecte apenas no conteúdo da narrativa, reflecte-se também na estrutura narrativa. Do ponto de vista emocional, os pais com escolaridade mais baixa, sendo menos sensíveis aos sentimentos das crianças e reprovando mais a actuação dessas sem o justificar, não proporcionam aos seus filhos oportunidades para integrar consistentemente as emoções com as acções. Utilizando o conceito de meta-emoção avançado por Gottman, Katz e Hooven (1997), parece-nos que os pais com nível de escolaridade mais baixo têm menos consciência das suas emoções e das dos seus filhos, não assumem as emoções das crianças como uma oportunidade de intimidade e de aprendizagem, não validam as emoções das crianças nem as nomeiam e, finalmente, não discutem as situações que desencadeiam as emoções, nem discutem os limites, os objectivos e as estratégias para lidar com essas emoções. Como veremos mais à frente, esse tipo de abordagem tem implicações na competência social das crianças. Do ponto de vista do conteúdo disciplinar, verificamos que os pais de escolaridade mais baixa explicitam menos o que pretendem que a criança faça e porquê, o que poderá ter implicações ao nível do desenvolvimento da capacidade da criança para reflectir sobre as situações de interacção quotidianas, perceber as relações causais entre as actuações dos diversos intervenientes e dar um sentido coerente a todas essas vivências. Daí os valores mais baixos em coerência narrativa.

Verificámos também que a escolaridade da mãe, comparativamente com a do pai, encontra-se correlacionada com um maior número de categorias, sendo a magnitude das correlações também superior. Isso significa que, à semelhança do que foi encontrado noutros estudos, o nível de escolaridade da mãe é a variável que mais influencia as respostas das crianças e que mais fortemente se encontra associada à parentalidade (Hoff \& cols., 2002), provavelmente porque as mães passam mais tempo em interacção com as crianças e supervisionam mais as suas vivências diárias.

No respeitante à relação entre as representações das crianças acerca das figuras parentais e a sua competência social, podemos concluir que os anos de escolaridade da mãe explicam em parte a relação entre as representações da criança e as escalas de auto-controlo, 
cooperação, asserção e competência académica, já que genericamente todas as correlações baixam. Por outro lado, os anos de escolaridade materna parecem moderar a relação entre as representações da criança e as escalas de problemas de comportamento, fortalecendo a associação entre essas variáveis.

Ao contrário de outras investigações (e.g., Amato \& Fowler, 2002; Shields \& cols., 2001), neste estudo a representação de comportamentos parentais de aceitação não se encontra associada de forma significativa a qualquer das escalas de competência social. De facto, as representações de aceitação, apesar de bastante frequentes, são pouco discriminativas, porque também não se relacionam com a escolaridade dos pais. Já relativamente à relação entre a representação de rejeição e a competência social, o mesmo não se verifica: as crianças que percepcionam os pais como rejeitantes são avaliadas pelas professoras como evidenciando menos comportamentos de auto-controlo e de asserção, mais problemas internalizados de comportamento (ansiedade, tristeza, solidão, baixa auto-estima) (e.g., Muris \& cols., 2003) e menos competência em termos académicos. Assim, as representações de afecto negativo são mais discriminativas do que as representações de afecto positivo o que nos leva a pensar que a existência de afecto positivo, só por si, não é suficiente para anular os efeitos do afecto negativo no desenvolvimento das crianças.

De entre os comportamentos disciplinares, a representação de punição física é a mais associada a resultados negativos nas crianças: as crianças que apresentam mais representações de punição física são avaliadas pelas professoras como sendo menos competentes em termos de habilidades sociais (auto-controlo, cooperação e asserção) e como apresentando mais problemas internalizados de comportamento. Esses resultados estão de acordo com a literatura (e.g., Cruz, 2005; Oppenheim \& cols., 1997; Shields \& cols., 2001). A representação de outros comportamentos disciplinares coercivos, como a punição não física, não apresenta qualquer relação com a competência social da criança; o mesmo se pode dizer em relação ao comportamento não confrontativo, apesar de ser o mais frequente. A representação dos comportamentos disciplinares com enfoque verbal, instrutivo e explicativo, pelo contrário, aparecem associados positivamente ao desenvolvimento da criança. Em particular, a indução aparece associada ao comportamento assertivo (pró-social), o que indica que a utilização de explicações pelos seus pais para ilustrar um argumento, parece funcionar como um modelo de assertividade para as crianças.

Da análise da relação entre competência social e coerência das narrativas verificou-se que as crianças que constroem narrativas coerentes em termos emocionais e narrativos são avaliadas como mais competentes pelas professoras em termos sociais e académicos. Tratando-se de resultados correlacionais, não é possível concluir qualquer relação de causa-efeito. Porém, esse resultado, coerente com alguma investigação já publicada (Oppenheim, 2003), parece sugerir que as crianças avaliadas como mais competentes revelam uma estrutura mental mais "organizada", que se traduz na sua capacidade para organizar em um todo coerente o conteúdo da sua narrativa e para identificar e justificar de forma coerente os estados emocionais associados às acções.

\section{Considerações Finais}

A título de conclusão gostaríamos de enfatizar que a Entrevista evidencia propriedades que autorizam a sua utilização em investigações subsequentes, permitindo recolher informação, de forma fidedigna, acerca das representações das crianças relativas a figuras parentais. A abordagem narrativa permite "dar voz às crianças" (Oppenheim, 2003, p. 148), recorrendo a uma tarefa que lhes é familiar e a que facilmente aderem.

O facto de os inícios de histórias corresponderem a situações hipotéticas não nos permitiu precisar, à partida, a extensão na qual as crianças se identificaram com o/a protagonista da história e, dessa forma, representaram os seus próprios pais. Essa potencial desvantagem, no entanto, afigura-se-nos simultaneamente como uma potencial vantagem, na medida em que a não personalização da situação descrita no início das histórias poderá ter facilitado a narrativa das crianças, reduzindo a probabilidade das suas respostas serem "contaminadas" pelo fenómeno da desejabilidade social e pela activação de mecanismos de defesa.

De uma forma global, os resultados obtidos permitemnos verificar uma elevada consistência das representações sobre a figura paterna e sobre a figura materna. As relações entre as respostas das crianças e a avaliação da sua competência social, realizada pelas professoras, permitem também afirmar a validade da Entrevista com referência a um critério externo. Confirma-se assim que a Entrevista constitui um instrumento que permite a avaliação das representações das crianças acerca das figuras parentais, diferenciando as suas respostas em função do seu nível de competência social. Nesse sentido, as representações das figuras parentais poderão constituir uma via para a compreensão das relações entre as acções parentais e a adaptação social da criança (Durning \& Fortin, 2000).

Em termos de estudos futuros, a Entrevista aqui apresentada será administrada em crianças com problemáticas específicas, tendo em vista analisar o seu valor como instrumento de despiste e de planeamento da intervenção em contextos educativos e clínicos.

\section{Referências}

Amato, P. \& Fowler, F. (2002). Parenting practices, child adjustment, and family diversity. Journal of Marriage and Family, 64, 703-716.

Bretherton, I. \& Oppenheim, D. (2003). The MacArthur Story Stem Battery: Development, administration, reliability, validity and reflections about meaning. Em R. D. Wolf \& D. Oppenheim (Eds.), Revealing the inner worlds of young children: The MacArthur Story Stem Battery and parent child narratives (pp. 55-80). New York: Oxford University Press.

Bretherton, I., Oppenheim, D., Buchsbaum, H., Emde, R. \& the MacArthur Narrative Group (1990). MacArthur Story Stem Battery. Unpublished manual, University of WisconsinMadison. 
Cain, K. (2003). Text comprehension and its relation to coherence and cohesion in children's fictional narratives. The British Journal of Developmental Psychology, 21, 335.

Carlson, E., Sroufe, A. \& Egeland, B. (2004). The construction of experience: A longitudinal study of representation and behavior. Child Development, 75, 1, 6-83.

Chuang, J. (2001). Agreement between categorical measurements: Kappa statistics. Retirado em 15/11/2004 de http://www.dmi. columbia.edu/homepages/chuangi/kappa/calculator.htm.

Cruz, O. (1999). O autocontrole em crianças de cinco anos: Implicações educativas das vivências familiares. Psicologia: Teoria, Investigação e Prática, 4, 109-130.

Cruz, O. (2005). Parentalidade. Coimbra: Quarteto Editores.

Custódio, S. (2005). Os pais como figuras de afecto e de disciplina. Um olhar sobre as representações das crianças de idade escolar acerca das figuras parentais._Dissertação de Mestrado, Faculdade de Psicologia e de Ciências da Educação da Universidade do Porto, Porto.

Durning, P. \& Fortin, A. (2000). Les pratiques éducatives parentales vues par les enfants. Enfance, 4, 375-391.

Emde, R. N. (2003). Early narratives: A window to the child's inner world. Em R. N. Emde, D. Wolf \& D. Oppenheim (Eds.), Revealing the inner worlds of young children: The MacArthur Story Stem Battery and parent child narratives (pp. 3-26). New York: Oxford University Press.

Gresham, F. M., \& Elliott, S. N. (1990). Social Skills Rating System manual. Circle Pines, MN: American Guidance Service.

Giles-Sims, J. Straus, M. \& Sugarman, D. (1995). Child, maternal, and family characteristics associated with spanking. Family Relations, 44, 170-176.

Glasgow, K., Dornbusch, S., Troyer, L., Steinberg, L. \& Ritter, P. (1997). Parenting styles, adolescents' attributions, and educational outcomes in nine heterogeneous high schools. Child Development, 68, 507-529.

Gottman, J. M., Katz, L. F. \& Hooven, C. (1997). Meta-emotion. How families communicate emotionally. Mahwah, NJ: Erlbaum.

Grych, J., Wachsmuth-Schlaefer, T. \& Klockow, L. (2002). Interparental aggression and young children's representations of family relationships. Journal of Family Psychology, 16, 259-272.

Hoff, E., Laursen, B. \& Tardif, T. (2002). Socioeconomic status and parenting. Em M. Bornstein (Ed.), Handbook of parenting, Vol. 2: Biology and ecology of parenting ( $2^{\mathrm{a}}$ ed., pp. 231-252). Mahwah: Lawrence Erlbaum.

Jacobsen, T. \& Hofmann, V. (1997). Children's attachment representations: Longitudinal relations to school behavior and academic competency in middle childhood and adolescence. Developmental Psychology, 33, 703-710.

Khaleque, A. \& Rohner, R. (2002). Perceived parental acceptancerejection and psychological adjustment: A meta-analysis of cross-cultural and intracultural studies. Journal of Marriage and Family, 64, 54-65

Lansford, J. E., Chang, L., Dodge, K. A., Malone, P. S., Oburu, P., Palmérus, K., Bacchini, D., Pastorelli, C., Bombi, A. S., Zelli, A., Tapanya, S., Chaudhary, N., Deater-Deckard, K., Manke, B., \& Quinn, N. (2005). Physical discipline and children's adjustment: Cultural normativeness as a moderator. Child Development, 76, 1234-1246.
Leaper, C. (2002). Parenting girls and boys. In M. Bornstein (Ed.), Handbook of parenting, Vol. 1: Children and parenting $\left(2^{\mathrm{a}} \mathrm{ed}\right.$., pp. 189-225). Mahwah: LEA.

Lemos, M. \& Meneses, H. (2002). A avaliação da competência social: Versão portuguesa da forma para professores do SSRS. Psicologia: Teoria e Pesquisa, 18, 267-274.

Macfie, J., Toth, S., Rogosch, F., Robinson, J., Emde, R. \& Cicchetti, D. (1999). Effect of maltreatment on preschoolers' narrative representations of responses to relieve distress and of role reversal. Developmental Psychology, 35, 460-465.

McDowell, D., Parke, R. \& Spitzer, S. (2002). Parent and child cognitive representations of social situations and children's social competence. Social Development, 11, 469-486.

Mueller, E. \& Tingley (1990). The Bear's Picnic: Children's representations of themselves and their families. New Directions for Child Development, 48, 47-65.

Muris, P., Meesters, C. \& van den Berg, S. (2003). Internalizing and externalizing problems as correlates of self-reported attachment style and perceived parental rearing in normal adolescents. Journal of Child and Family Studies, 12, 171-183.

Niec, L. \& Russ, S. (2002). Children's internal representations, empathy, and fantasy play: A validity study of the SCORS-Q. Psychological Assessment, 14, 331-338.

Oppenheim, D. (2003). Children's emotional resolution of MSSB narratives: Relations with child behavior problems and parental psychological distress. Em R. Emde, D. Wolf \& D. Oppenheim (Eds.), Revealing the inner worlds of young children: The MacArthur Story Stem Battery and parent child narratives (pp. 147-162). New York: Oxford University Press.

Oppenheim, D. \& Waters, E. (1995). Narrative processes and attachment representations: Issues of development and assessment. Em E. Waters, B. Vaughn, G. Posada \& K. Kondo-Ikemura (Eds.), Caregiving, cultural, and cognitive perspectives on secure-base behavior and working models: New growing points of attachment theory and research. Monographs of the Society for Research in Child Development, 60, 197-215.

Oppenheim, D., Emde, R. \& Warren, S. (1997). Children's narrative representations of mothers: Their development and associations with child and mother adaptation. Child Development, 68, 127-138.

Pinderhughes, E. E., Dodge, K. A., Bates, J. E., Pettit, G. S. \& Zelli, A. (2000). Discipline responses: Influences of parents' socioeconomic status, ethnicity, beliefs about parenting, stress, and cognitive-emotional processes. Journal of Family Psychology, 14, 380-400.

Reid, M., Ramey, S. \& Burchinal, M. (1990). Dialogues with children about their families. New Directions for Children Development, 48, 5-27.

Richman, A., Miller, P. \& LeVine, R. (1992). Cultural and educational variations in maternal responsiveness. Developmental Psychology, 28, 614-621.

Robinson, J., Hérot, C., Haynes, P. \& Mantz-Simmons, L. (2000). Children's story stem responses: A measure of program impact on developmental risks associated with dysfunctional parenting. Child Abuse \& Neglect, 24, 99-110.

Robinson, J., Mantz-Simmons, L., Macfie, J., Kelsay, K. \& the MacArthur Narrative Working Group (2001). MacArthur Narrative Coding Manual. Unpublished manuscript. 
Rubin, K. H. \& Mills, R. S. L. (1992). Parents' thoughts about children's socially adaptive and maladaptive behaviors: stability, change, and individual differences. Em I. E. Sigel, A. V. McGillicuddy-DeLisi \& J. J. Goodnow (Eds), Parental belief systems. The psychological consequences for children_( $2^{\mathrm{a}}$ ed., pp. 41-70). Hillsdale, NJ: Erlbaum.

Shields, A., Ryan, R. \& Cicchetti, D. (2001). Narrative representations of caregivers and emotion dysregulation as predictors of maltreated children's rejection by peers. Developmental Psychology, 37, 321-337.

Solomonica-Levi, D., Yirmiya, N., Erel, O., Samet, I. \& Oppenheim, D. (2001). The associations among observed maternal behaviour, children's narrative representations of mothers, and children's behaviour problems. Journal of Social and Personal Relationships, 18, 673-690.
Sorbring, E., Rödholm-Funnemark, M. \& Palmérus, K. (2003). Boys' and girls' perceptions of parental discipline in transgression situations. Infant and Child Development, 12, 53-69.

Straus, M. \& Stewart, J. (1999). Corporal punishment by American parents: National data on prevalence, chronicity, severity, and duration, in relation to child and family characteristics. Child and Family Psychology Review, 2, 55-70.

Recebido em 02.04.2007

Primeira decisão editorial em 20.03.2008

Versão final em 21.04.2008

Aceito em 15.10.2008 